\title{
Treatment of Women with Multiple Sclerosis Planning Pregnancy
}

Kristen M. Krysko, MD MAS ${ }^{1,2, *}$ ๑ Riley Bove, MD MSC ${ }^{1}$

Ruth Dobson, MRCP PhD ${ }^{3,4}$

Vilija Jokubaitis, $P h D^{5,6}$

Kerstin Hellwig, $M D^{7}$

\author{
Address \\ ${ }^{1}$ UCSF Weill Institute for Neurosciences, Department of Neurology, University of \\ California San Francisco, 675 Nelson Rising Lane, San Francisco, CA, 94158, USA \\ ${ }^{*}, 2$ Division of Neurology, Department of Medicine, St. Michael's Hospital, Univer- \\ sity of Toronto, 9 Donnelly Wing South, 30 Bond Street, Toronto, Ontario, M5B \\ 1W8, Canada \\ Email: Kristen.krysko@mail.utoronto.ca \\ ${ }^{3}$ Preventive Neurology Unit, Wolfson Institute of Preventive Neurology, Queen \\ Mary University of London, Charterhouse Square, London, UK \\ ${ }^{4}$ Department of Neurology, Royal London Hospital, Whitechapel, London, UK \\ ${ }^{5}$ Department of Neuroscience, Monash University, Melbourne, VIC, Australia \\ ${ }^{6}$ Department of Neurology, Alfred Health, Melbourne, VIC, Australia \\ ${ }^{7}$ Department of Neurology, St. Josef Hospital, Ruhr University Bochum, Bochum, \\ Germany
}

Published online: 30 March 2021

(C) The Author(s), under exclusive licence to Springer Science+Business Media, LLC part of Springer Nature 2021

This article is part of the Topical Collection on Multiple Sclerosis and Related Disorders

Keywords Multiple sclerosis - Pregnancy · Postpartum · Lactation - Disease-modifying therapy · COVID-19

\begin{abstract}
Purpose of Review We review data available for treatment of multiple sclerosis (MS) before, during, and after pregnancy. We present recent data on disease-modifying therapies (DMT) before/during pregnancy and while breastfeeding, with treatment recommendations. Recent Findings Observational data support the safety of injectable DMTs (glatiramer acetate, interferon-beta) for use in pregnancy, while some oral DMTs might be associated with fetal risk. Monoclonal antibodies (mAbs) before pregnancy such as rituximab or natalizumab likely do not pose significant fetal risks, but can cross the placenta with neonatal hematological abnormalities if given in the second trimester or later. Breastfeeding is associated with decreased risk of postpartum relapses. Finally, injectables and mAbs likely have low transfer into breastmilk.
\end{abstract}


Summary Many women with MS do not require DMTs during pregnancy, although injectables could be continued. For women with highly active MS, cell-depleting therapies could be given before conception, or natalizumab could be continued through pregnancy, with monitoring of the fetus. Women should be encouraged to breastfeed, and those with higher relapse risk could consider injectables or mAbs while breastfeeding. Further data on safety of DMTs around pregnancy are needed. Maximizing function through nonpharmacologic approaches is complementary to DMTs. Special considerations for pregnancy and DMTs during the COVID-19 pandemic are needed.

\section{Introduction}

Multiple sclerosis (MS) is an autoimmune demyelinating and degenerative disease of the central nervous system (CNS). MS typically has an initial relapsing-remitting course, with episodes of inflammatory CNS injury that usually remit, at least partially (relapsing-remitting MS (RRMS)). Approximately 5-15\% of patients instead have a progressive course from onset, known as primary progressive MS (PPMS) [1]. MS is typically diagnosed between the ages of 20 and 40, and more commonly in women than men. The sex ratio in RRMS has been steadily rising since the 1950 s and is about 3:1 $[2,3]$. Therefore, the burden of early disease is disproportionately weighted towards women of childbearing age.

Historically, women with MS were discouraged from having children. This view has changed since the late 1990s, following the seminal pregnancy in MS (PRIMS) study. PRIMS demonstrated that relapse activity diminished during pregnancy especially in the third trimester, although it increased postpartum [4]. This finding has been replicated in numerous studies that show between 14 and $31 \%$ of women experience a relapse in the first 3 months postpartum [4-7]. In more recent, milder and population-based MS cohorts, this postpartum relapse risk may be attenuated [ $8 \bullet$. Studies have not identified a clear impact of pregnancy itself on long-term disability $[9,10]$, although pregnancy-associated relapses likely have an impact [11].

Since 2000, 9 new MS disease-modifying therapies (DMTs), together with a number of generic equivalents, have come to market. Ten classes of DMTs are now available for RRMS [12]. Ocrelizumab, an anti-CD20 Bcell depleting therapy, became the first drug approved in 2017/2018 for PPMS [13], and rituximab is used offlabel. The introduction of more effective therapies has led to disease stabilization in patients previously refractory to available therapies and an associated increase of women with moderate disability attempting pregnancy $[7,14 \bullet, 15]$. Not all MS therapies are suitable for use in women planning pregnancy due to potential teratogenicity. While it may seem sensible to discontinue DMTs in women planning to conceive, extended drug holidays may lead to re-emergence of disease activity. The management of women with MS of childbearing potential thus requires a plan covering pregnancy planning, pregnancy, and the postpartum period. Disease activity, impact of therapy withdrawal, and effects of MS therapy on the fetus, together with any plan for breastfeeding, should all be considered. While the world grapples with the COVID-19 pandemic, it is also pertinent to consider the impacts of the SARS-CoV-2 virus on pregnancy in MS.

In this review, we discuss pharmacologic treatment options while planning pregnancy, during pregnancy, and postpartum in women with MS. We further discuss breastfeeding options and physical therapy as a means of disease management during this period. Finally, we discuss the impact of COVID-19 infection on pregnancy and its implications for MS pregnancy.

\section{Treatment}

\section{Pharmacologic treatment when planning pregnancy and during pregnancy}

When discussing treatment of MS in women of reproductive age, counseling should include discussion of DMT safety before and during pregnancy. Since relapses typically decrease during pregnancy, most women are able to safely 
discontinue treatment for pregnancy. Relapse risk is highest in the first trimester of pregnancy, which should be considered when timing DMT discontinuation. Women with more active MS or on DMTs with risk of disease reactivation upon discontinuation should carefully plan treatment before pregnancy to decrease relapse risk.

As a general rule, to avoid teratogenicity, a medication should be discontinued at least 5 maximal half-lives prior to conception. However, recent, albeit limited, data have enabled more specific evaluation of DMT safety during pregnancy. Ideally 1000, and at least 300, first trimester-exposed pregnancies are needed to assess medication safety during pregnancy [16]. Data currently available for pregnancy exposure, as well as our recommendations based on evaluation of DMT half-lives and risks, are in Table 1.

The most data on first-trimester exposure are available for the injectables, including glatiramer acetate and interferon-betas, which demonstrate these are safe to continue to conception. There are less data available for exposure throughout pregnancy, since most women discontinue DMT when aware of pregnancy in the first trimester. The most data exist for entire pregnancy exposure with glatiramer acetate, and it is likely safe to continue throughout pregnancy. The European Medicines Association (EMA) and Food and Drug Administration (FDA) both recently updated their labels for interferon beta-1a indicating there is no increased risk with early pregnancy exposure in humans, and the EMA specifies this may be considered during pregnancy $[17,18]$. FDA label updates are expected for other interferon-betas.

Data for oral DMTs are heterogeneous. There does not appear to be increased risk of spontaneous abortion or congenital abnormalities with dimethyl fumarate in human studies. Its half-life is short, so it can be discontinued when attempting pregnancy or upon a positive pregnancy test, although continuation in early pregnancy requires weighing risks and benefits given $<300$ reported pregnancy exposures [19-21]. Risks with diroximel fumarate are expected to be similar, although data are lacking [22].

There is concern for a two-fold increased risk of congenital malformations with fingolimod, so it must be discontinued at least 2 months before attempting conception [23-25]. Unfortunately, fingolimod discontinuation may result in disease reactivation during the conception period or pregnancy [14•], so bridging therapy before pregnancy should be planned carefully, although relapse risk during the transition is unclear. Data are not yet available for siponimod [26], but it likely has similar effects, although its shorter half-life allows discontinuation 10 days prior to conception. There are limited human data for cladribine exposure in pregnancy, although embryolethality and malformations occurred in exposed animals, and pregnancy should only be attempted at least 6 months after the last cladribine dose for both women and men [2729]. Cladribine has long-lasting benefit for MS after drug elimination, so it may be an option in women planning pregnancy in advance, as long as pregnancy is not attempted until 6 months after the last dose. Teriflunomide is contraindicated for pregnant women due to embryolethality and teratogenicity in animals, and an accelerated elimination protocol with confirmation of serum level $<0.02 \mathrm{mg} / \mathrm{L}$ is required before attempting conception and is also suggested by the FDA for men [30-32]. Interestingly, in humans, the prevalence of major malformations was not increased after exposure to teriflunomide or leflunomide in a limited sample ( $>400$ pregnancies) [32]. 
Table 1. Recommendations for disease-modifying therapy use in pregnancy and data on pregnancy exposure

\begin{tabular}{|c|c|c|c|}
\hline DMT & Exposure in first trimester & $\begin{array}{l}\text { Exposure through } \\
\text { pregnancy }\end{array}$ & $\begin{array}{l}\text { Recommendations for use } \\
\text { before and during pregnancy* }\end{array}$ \\
\hline \multicolumn{4}{|l|}{ Injectable } \\
\hline $\begin{array}{l}\text { Glatiramer } \\
\text { acetate }[60]\end{array}$ & $\begin{array}{l}\text { No elevated risk for SA or CA in } n> \\
2500 \text { [90-94] }\end{array}$ & $\begin{array}{l}\text { No elevated risk of } \\
\text { adverse pregnancy } \\
\text { outcomes in } \\
n<250[91,94-96]\end{array}$ & $\begin{array}{l}\text {-May continue until positive } \\
\text { pregnancy test, or if more active, } \\
\text { can continue during pregnancy }\end{array}$ \\
\hline $\begin{array}{l}\text { Interferon- } \beta \\
{[17,18} \\
97-100]\end{array}$ & $\begin{array}{l}\text { No elevated risk for SA or CA in } n> \\
2500[93,101-104]\end{array}$ & $\begin{array}{l}\text { No elevated risk of } \\
\text { adverse pregnancy } \\
\text { outcomes in } \\
n<100 \text { [91, } 95 \\
102-104]\end{array}$ & $\begin{array}{l}\text {-May continue until positive } \\
\text { pregnancy test, or if more active, } \\
\text { can continue during pregnancy }\end{array}$ \\
\hline \multicolumn{4}{|l|}{ Oral } \\
\hline $\begin{array}{l}\text { Dimethyl } \\
\text { fumarate }[19, \\
20]\end{array}$ & $\begin{array}{l}\text { Risk of SA and CA not elevated; } n= \\
263 \text { with } 214 \text { known outcomes } \\
\text { [21] with risk of SA 16/214 (7\%) } \\
\text { and risk of CA } 7 / 214(4 \%)\end{array}$ & N/A & $\begin{array}{l}\text {-Stop with contraception or upon } \\
\text { positive pregnancy test } \\
\text {-If accidental pregnancy exposure: } \\
\text { stop } \\
\text {-EMA: may use during pregnancy only } \\
\text { if potential benefit justifies risk to the } \\
\text { fetus }\end{array}$ \\
\hline $\begin{array}{l}\text { Diroximel } \\
\text { fumarate [22] }\end{array}$ & $\begin{array}{l}\text { Risk of SA and CA unknown but likely } \\
\text { similar to dimethyl fumarate }\end{array}$ & N/A & $\begin{array}{l}\text {-Stop with contraception or upon } \\
\text { positive pregnancy test } \\
\text {-If accidental pregnancy exposure: } \\
\text { stop }\end{array}$ \\
\hline $\begin{array}{l}\text { Fingolimod } \\
{[23,24]}\end{array}$ & $\begin{array}{l}\text { 2-fold higher risk of major CA } \\
\text { (congenital heart disease, renal, } \\
\text { musculoskeletal abnormalities) in } \\
\text { a registry; } n=113 \text { live births with } \\
6.2 \% \text { major } \\
\text { malformations; Novartis Safety } \\
\text { Database } 3.7 \% \\
\text { (25/678); Pregnancy outcomes } \\
\text { Intensive Monitoring (PRIM) pro- } \\
\text { gram } 2 \% \text { (8/393) [25] }\end{array}$ & N/A & $\begin{array}{l}\text {-Stop } 2 \text { months before conception } \\
\text { and discuss bridging with another } \\
\text { DMT } \\
\text {-If accidental pregnancy exposure: } \\
\text { stop and organ screening ultrasound } \\
\text {-EMA: contraindicated without } \\
\text { effective contraception and during } \\
\text { pregnancy } \\
\text {-FDA: use effective contraception and } \\
\text { avoid pregnancy during and for } \\
2 \text { months after stopping }\end{array}$ \\
\hline $\begin{array}{l}\text { Siponimod } \\
{[26]}\end{array}$ & $\begin{array}{l}\text { Risk of CA unknown, but likely similar } \\
\text { to fingolimod }\end{array}$ & N/A & $\begin{array}{l}\text {-Stop } 10 \text { days before conception and } \\
\text { discuss bridging with another DMT } \\
\text {-If accidental pregnancy exposure: } \\
\text { stop and organ screening ultrasound } \\
\text {-FDA: use effective contraception and } \\
\text { avoid pregnancy during and for } \\
10 \text { days after stopping }\end{array}$ \\
\hline $\begin{array}{l}\text { Cladribine } \\
{[27,28]}\end{array}$ & $\begin{array}{l}\text { Risk of CA unknown; } n=16 \\
\text { pregnancies within } 6 \text { months of } \\
\text { cladribine } \\
\text { (10 elective terminations; } \\
2 \text { SA; } 1 \text { ectopic; } 3 \text { healthy) [29]; } \\
n=8 \text { exposed in pregnancy }\end{array}$ & $\mathrm{N} / \mathrm{A}$ & $\begin{array}{l}\text {-Pregnancy safe } 6 \text { months after last } \\
\text { dose } \\
\text {-Interaction between cladribine and } \\
\text { oral contraception: } \\
\text { women must also use mechanical }\end{array}$ \\
\hline
\end{tabular}


Table 1. (Continued)

DMT

\begin{tabular}{|c|c|}
\hline & $\begin{array}{l}\text { (4 elective terminations } \\
\text { (1 with fetal defects); } \\
2 \text { SA; } 2 \text { live births) [105] }\end{array}$ \\
\hline $\begin{array}{l}\text { Teriflunomide } \\
{[30,31]}\end{array}$ & $\begin{array}{l}\text { No elevated risk of CA; } n \\
=437 \text { with } 222 \text { known outcomes } \\
\text { (major malformation } 3.6 \%(1 / 28) \\
\text { in clinical trials, } 0 \%(0 / 51) \text { in } \\
\text { post-marketing data) [32] }\end{array}$ \\
\hline \multicolumn{2}{|l|}{ Infusion } \\
\hline $\begin{array}{c}\text { Natalizumab } \\
{[106,107]}\end{array}$ & $\begin{array}{l}\text { SA and CA risk likely not elevated } \\
{[108] ; n=369 \text { with } 355 \text { known }} \\
\text { outcomes with } 9.0 \% \text { SA and } 5.05 \% \\
\text { CA }[109] ; n=92,17.4 \% \text { SA and } \\
3.7 \% C A[108] ; n=98,17.3 \% \text { SA } \\
\text { and } 5.2 \% \text { CA }[110]\end{array}$ \\
\hline
\end{tabular}

Rituximab Reduced B-cell count in newborns

$[41,42]$

Ocrelizumab

$[34,35]$

Alemtuzumab

Cannot exclude a slightly elevated

$[45,46]$

\section{Exposure in first trimester} Risk for SA and CA likely not elevated; $n=102$ with $12 \%$ SA and $4.5 \%$ CA or medical conditions [36] but recent study $n=74$ with $\sim 30 \%$ SA and 1/38 live births with perinatal ischemic stroke (last RTX 9.5 months pre-conception) [38••]

Risk for SA likely not elevated; $n=118$ with 54 known outcomes with $7.4 \%$ (4/54) SA and 3\% (1/32 at risk) stillbirth [37]

risk for $\mathrm{SA} ; n=233$ known outcomes
$\mathrm{N} / \mathrm{A}$

\section{Exposure through pregnancy}

Cytopenias [50];

anemia \pm thrombocytopenia $(4 / 5)$, low birth weight, increased first year hospitalizations [40••]; malformations (4/31; mainly cardiac/pulmonary) and anemia (5/31) [51]

Reduced B-cell count in newborns [36, 39] with 22\% SA, 0\% CA, 0.4\% stillbirth [111]

\section{Limited [37]; 1 case of T2 exposure with reduced $\mathrm{B}$-cells in newborn [40••]}

N/A

\section{Recommendations for use before and during pregnancy*}

contraception for $\geq 4$ weeks after last dose

-Stop before conception with accelerated elimination (serum level $<0.02 \mathrm{mg} / \mathrm{L}$ twice, 2 weeks apart)

-If accidental pregnancy exposure: stop, accelerated elimination, organ screening ultrasound

-FDA/EMA: contraindicated in pregnancy

-May switch to depleting agent before pregnancy

-May stop with positive pregnancy test but risk of disease reactivation -Highly active: continue in pregnancy (every 8 weeks and last dose 34 weeks), evaluate neonate for hematological abnormalities

\footnotetext{
-Attempt conception 1-3 months after last dose

-Discontinue in case of pregnancy -Re-dose if not pregnant after 6-9 months
}
-Attempt conception 1-3 months after last dose
-Discontinue in case of pregnancy -Re-dose if not pregnant after 6-9 months
-Attempt conception 4 months after last dose
-Pregnancy test before each course -Monitor thyroid function and antithyroid antibodies (placental transfer of antibodies with neonatal Graves' disease reported) [45]


Table 1. (Continued)

DMT

Exposure in first trimester

Exposure through pregnancy
Recommendations for use before and during pregnancy*

CA congenital abnormality, DMT disease-modifying therapy, EMA European Medicines Agency, FDA Food and Drug Administration, N/A not available, $R T X$ rituximab, $S A$ spontaneous abortion, $T 2$ second trimester

* Recommendations for timing of DMT use around pregnancy represent expert opinion based on available data

Even if women accidentally become pregnant while on potentially "dangerous" DMTs, most embryos will develop normally based on current knowledge. Therefore, it is important to carefully counsel women individually using the most updated safety data in the case of accidental pregnancy exposure. An elective termination per se is not necessary.

Some monoclonal antibody therapies (mAbs) offer advantages for use during pregnancy planning, including long-lasting biological effect and benefit on disease activity after drug elimination, as well as limited placental transfer of IgG during the first trimester [33]. A dilemma in using mAbs before pregnancy includes conservative product labels; for example, pregnancy is only recommended at least 12 months after ocrelizumab infusion by the EMA [34] compared to 6 months by the FDA [35]. Risks for congenital malformations are likely not elevated with rituximab [36] or ocrelizumab [37]. A slightly higher risk for spontaneous abortion with rituximab was found in a recent populationbased sample of 74 pregnancies in MS [38••], but not in a prior systematic review of 102 pregnancies treated for various conditions [36]. Low B-cell counts in newborns whose mothers received rituximab $[36,39]$ or ocrelizumab [40••] during pregnancy have been reported, and cord blood should be checked. Based on their half-lives, these drugs are typically eliminated by 3.5-4.5 months after an infusion [34, 35, 41,42], and since IgG does not cross the placenta until the second trimester, pregnancy may be attempted 1-3 months after rituximab or ocrelizumab in women with more active MS. This minimizes fetal exposure while offering immunomodulatory benefit for several additional months [43•]. If pregnancy is not achieved by 6-9 months after dosing, women could be infused while delaying conception attempts for an appropriate period. For antiCD20 mAbs, uncertainty remains regarding infection risk, especially for women with longer duration of use and/or low immunoglobulins. Limited data exist on use of anti-CD20 mAbs during pregnancy, and this should be reserved for women with aggressive MS or neuromyelitis optica spectrum disorders (NMOSD) [44]. Alemtuzumab also offers prolonged immunomodulatory effects after drug elimination and is another option in childbearing years, with conception 4 months after the last infusion to limit fetal exposure [45, 46]. There is a high risk of autoimmune thyroid disease with alemtuzumab, so thyroid function monitoring must continue during pregnancy [45].

In contrast to other mAbs, natalizumab's biological effects are not as longlasting. Redosing is required every $4-8$ weeks, with risk of disease reactivation upon discontinuation [47-49•]. Risks of spontaneous abortion and congenital malformation are likely not elevated with natalizumab, but exposure 
throughout pregnancy is associated with hematological abnormalities [40••, $50,51]$, low birth weight, and increased hospitalizations in the first year of life $[40 \bullet \bullet$. Natalizumab discontinuation at the time of a positive pregnancy test or

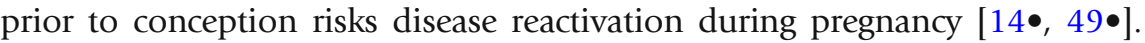
Options for limiting this risk include switching to a depleting agent prior to pregnancy $[36,43 \bullet]$, or for women with historically active disease, continuing natalizumab every 8 weeks until 34 weeks gestation $[40 \bullet \bullet, 51]$. With late pregnancy exposure, the neonate should be evaluated for cytopenias [50].

Pregnancy planning for women with MS thus depends on the severity of their MS and current DMT. Women with mild disease not on DMTs associated with disease reactivation may choose to stop DMT before conception. In women with less active disease, injectable therapies may be continued until a positive pregnancy test or throughout pregnancy. The decision to continue injectables during pregnancy should be made with a careful risk-benefit evaluation, since data on exposure beyond the first trimester are scarce. Part of this should include discussion about the time taken to achieve full biological effect upon DMT resumption. In women with more active disease, or for those discontinuing therapies associated with disease reactivation (e.g., fingolimod, natalizumab), the use of highly effective induction/interrupted dosing therapies such as rituximab, ocrelizumab, alemtuzumab, or cladribine may be considered before pregnancy with appropriate washout depending on the DMT, without further dosing during pregnancy. Women with PPMS may similarly use B-cell depleting therapies before conception. More data on the safety of these approaches and magnitude of relapse risk when switching DMTs are needed.

Women with MS should be counseled on the importance of folatecontaining prenatal vitamins. Additionally, vitamin D3 should be supplemented before and during pregnancy, targeting mid- to high-normal blood levels, with up to 4000 IU vitamin D3 daily acceptable. Symptomatic therapies such as for fatigue, depression, spasticity, and ambulation should be discussed with the neurologist and obstetrician in advance of pregnancy, as many of these have associated fetal risks and should be discontinued before conception.

In the case of relapse during pregnancy, a short course of high-dose corticosteroids can be considered. This is often limited to severe relapses, especially in the first trimester since fetal risks such as orofacial cleft and reduced birth weight cannot be excluded [52] and due to risk of precipitating gestational diabetes. Methylprednisolone or prednisone is preferred given less fetal exposure compared with dexamethasone or betamethasone. This is because the placental transfer of dexamethasone or betamethasone could result in utero effects such as promoting fetal lung maturity, as well as possibly longer term neurodevelopmental effects [53]. For more severe relapses unresponsive to high-dose steroids, plasma exchange may be considered [54].

Exclusive breastfeeding for at least 6 months is recommended by the World Health Organization and American Academy of Pediatrics due to significant infant and maternal health benefits [55]. Breastfeeding is also recommended for women with MS as it has not been shown to be harmful and is likely protective against postpartum relapses. A systematic review and meta-analysis published in 2020 included 24 studies and pooled data from 16 studies, 
demonstrating that breastfeeding was associated with a 37\% lower odds of postpartum relapse on average compared to not breastfeeding [56•]. It is difficult to exclude confounding, whereby women with milder MS may be more likely to breastfeed off DMT. However, in the 4 studies controlling for confounding, breastfeeding remained protective, with $43 \%$ lower rate of postpartum relapse with breastfeeding [56•]. The protective effect of breastfeeding on relapses appears to be time-limited, in the first 6 months postpartum [8・, and also limited to exclusive breastfeeding (no regular formula supplementation for $\geq 2$ months) rather than partial breastfeeding $[8 \bullet, 57]$.

\section{Safety of pharmacological agents with breastfeeding}

There have historically been a lack of data and guidance for DMT use while breastfeeding, and overall, more lactation studies of DMTs, as well as evaluation of long-term safety in infants exposed to DMTs in breastmilk, are needed to better understand associated risks. Generally, several factors influence drug transfer to breastmilk, such as molecular weight, lipid solubility, protein binding, volume of distribution, transport mechanisms, and breastmilk stage (more transfer to colostrum than mature milk) [58]. Other factors to consider include oral bioavailability of a drug in an infant if it enters the breastmilk and potential toxicity of a particular drug to the infant. Despite theoretical understanding of drug transfer based on drug properties and animal lactation studies, human studies are necessary to evaluate drug transfer to breastmilk in treated women. The relative infant dose (RID) is a measure of drug breastmilk transfer and is the percentage of maternal dose consumed through breastmilk in $24 \mathrm{~h}$ ([breastmilk drug concentration $(\mathrm{mg} / \mathrm{L})^{*} 0.15 \mathrm{~L} / \mathrm{kg} /$ day* maternal weight $\left.(\mathrm{kg})\right] /$ maternal dose (mg)). RID values of less than $10 \%$ are generally acceptable for breastfeeding, although toxicity of the drug also influences safety while breastfeeding [59].

Based on currently available data, the injectables and mAb DMTs are likely compatible with breastfeeding, while oral DMTs are most likely less safe during lactation, at least theoretically, but data on breastmilk transfer is not available for most drugs (Table 2). Among the injectables, glatiramer acetate is a large molecule suggesting limited transfer to breastmilk without expected adverse effects to the infant, although there are neither animal nor human studies of transfer into breastmilk [60]. Interferon-betas are also large molecules, with a human study showing an acceptable RID of $0.006 \%$ [61]. This suggests interferon-betas are compatible with breastfeeding, and interferon-beta was recently approved for use during lactation by the EMA [17], and the FDA updated the label with data of low presence of interferon beta-1a in breastmilk although did not specifically approve use during lactation [18, 62].

There is reassuring evidence from a recent systematic review that infused IgG1 monoclonal antibodies, which are large molecules, transfer in minute quantities into breastmilk [63•]. Further, even if ingested in milk, they have limited oral bioavailability. Although some undigested IgG molecules enter the neonatal circulation through the neonatal Fc receptor in rodents, this oral absorption appears to be much lower in humans [64]. To date, studies have not noted negative effects on infant health of those breastfeeding from mothers treated with mAbs $[63 \bullet, 65]$. IgG1 monoclonal antibodies used for MS include alemtuzumab, ocrelizumab, and rituximab. There is low breastmilk transfer of rituximab with median RID $0.08 \%$ (range $0.06-0.10 \%$ ), suggesting this is 
compatible with breastfeeding [66・•]. Further, normal B-cell counts have been reported in 5 infants who received rituximab or ocrelizumab while breastfeeding [40••]. Studies of breastmilk transfer are needed for alemtuzumab and ocrelizumab, although it is expected that transfer would be similarly low, and that infused IgG1 molecules would not enter the neonatal circulation in biologically relevant amounts. Natalizumab, an IgG4 molecule, might have greater transfer into breastmilk, with an estimated RID of up to 5.3\% [67]. Although there is theoretical concern for cumulative effects with monthly dosing, a recent study found no evidence of natalizumab accumulation in breastmilk after up to 4 infusions, and no anemia or other adverse outcomes in 2 infants exposed only through breastmilk $[40 \bullet \bullet$ ]. One infant with third trimester natalizumab exposure had detectable natalizumab in the serum at birth, but no detectable natalizumab later while breastfeeding despite ongoing maternal natalizumab treatment $[40 \bullet \bullet]$. This suggests that the breastfeeding infant does not significantly absorb natalizumab.

Unfortunately, the small molecular weight of oral DMTs may allow transfer into breastmilk, and their oral bioavailability raises the likelihood of absorption if breastmilk is ingested by the infant. Transfer of fingolimod, siponimod, and teriflunomide into breastmilk has been demonstrated in animal studies [23, 24, $26,30,31]$, but there are no reported human studies. At this time, oral DMTs are not recommended, and cladribine is specifically contraindicated $[27,28]$ while breastfeeding. However, due to its cyclic administration and short half-life, breastfeeding is an option 7 (EMA) or 10 (FDA) days after the last cladribine tablet.

Methylprednisolone, which is used to both prevent and treat relapses postpartum, has transfer to breastmilk [68, 69]. The largest study included 9 patients treated for acute relapse with $1000 \mathrm{mg}$ IV methylprednisolone daily for 3 days, and 7 patients treated once monthly on a prophylactic basis; RID was $0.71 \%$, which is well within the acceptable range [68]. Given the short duration of pulse steroids used for relapses or prophylaxis, infant exposure would be low even if breastfeeding $1 \mathrm{~h}$ post-infusion, and delaying breastfeeding $2-4 \mathrm{~h}$ from the infusion would further limit exposure.

There is concern for increased risk of postpartum MS relapses [4], although this risk was lower in a recent milder population-based MS cohort [8•]. In women who do not plan to breastfeed or who cannot due to maternal or neonatal factors, then rapid resumption of DMT within 2-4 weeks postpartum is recommended. Given the protective effect of breastfeeding on MS relapses, women with MS wishing to breastfeed should be encouraged to breastfeed exclusively, if possible, for the first 6 months; many may experience stability [8•]. For women with more active MS, additional treatment strategies including DMTs can be considered for use while breastfeeding to further reduce postpartum relapse risk. For these women, when considering whether or not to resume DMTs before weaning, clinicians and patients should consider the risk of postpartum relapses and potential adverse effects of DMT use during breastfeeding to the infant. For women with more active MS and higher risk of postpartum relapses, the benefits of both breastfeeding and using injectable or mAb DMTs may outweigh theoretical risks to the infant. Similarly, mAb use 
while breastfeeding has been recommended for NMOSD [44].

If relapses occur postpartum, corticosteroids are first-line treatment, and corticosteroids may also occasionally be given postpartum to prevent relapses with limited supportive data [70]. Methylprednisolone can be used during breastfeeding since transfer to breastmilk is low, as noted above [68, 69]. Intravenous immune globulin (IVIG) is not a standard treatment for MS relapses, and while controversial, recent data have not supported its use in prophylaxis against postpartum relapses [71]. Furthermore, risks of venous thromboembolism associated with IVIG are of particular concern in the postpartum period when this risk is already elevated.

\section{Providing whole-patient care before, during, and after pregnancy}

Many women with MS report improved symptoms during pregnancy. However, pregnancy can impact specific functional domains such as cardiovascular conditioning, spasticity, and mood. Since these have not been rigorously evaluated in MS, there are limited data to guide care, and therefore we describe our combined clinical experience. As a general principle, monitoring may include comprehensively evaluating and treating the following functions and when warranted multidisciplinary referrals (e.g., psychologist, psychiatrist, physical therapist, pelvic floor therapist, and/or urologist).

\section{Ambulatory function and physical therapy}

Walking is a primary form of exercise in people with MS [72] and is generally considered safe for pregnant women [73•]. Prior to pregnancy, attention to body weight and cardiovascular fitness could both improve fecundability and optimize physical functioning during gestation. During pregnancy, attention may be paid to spasticity, pain, and balance. When possible, dialog between the obstetric and rehabilitation provider is recommended, particularly in women deemed at higher obstetric risk (e.g., cervical insufficiency, multiple gestation) [73•]. Postpartum, women may be evaluated for cardiopulmonary deconditioning, focal weakness, spasticity, and balance. Exercise may also help improve mood postpartum [73•].

\section{Bladder function and pelvic floor physical therapy}

Because bladder and bowel function can be impacted both by neurogenic and obstetrical causes $[74,75]$, these should be evaluated and optimized prior to pregnancy, and again in the postpartum period. Neurogenic bladder from MS may result in urinary urgency, urge incontinence, and/or retention, while pregnancy and vaginal delivery may result in stress urinary incontinence. Pelvic floor therapy is a recommended first-line treatment for both causes, prior to medications [76]. Urinary tract infections should also be proactively diagnosed and treated, as these are common in MS and pregnancy, and are associated with adverse pregnancy outcomes [77].

\section{Mental health and psychosocial well-being}

Comprehensive care includes evaluating the patient's baseline mood (depression and anxiety) and fatigue levels, availability of social support [78], and specific work-related or financial constraints. Mood management is particularly 
Table 2. Transfer of disease-modifying therapies to breastmilk and recommendations for use while breastfeeding

\begin{tabular}{|c|c|c|c|}
\hline DMT & Transfer to breastmilk & $\begin{array}{l}\text { Relative infant } \\
\text { dose (RID) }\end{array}$ & $\begin{array}{l}\text { Recommendation for use while } \\
\text { breastfeeding* }\end{array}$ \\
\hline \multicolumn{4}{|l|}{ Injectable } \\
\hline $\begin{array}{l}\text { Glatiramer } \\
\text { acetate [60] }\end{array}$ & $\begin{array}{l}\text { Unknown. Likely low given large MW } \\
(4700-13,000 \mathrm{Da}) \text { but broken } \\
\text { rapidly into amino acid } \\
\text { components }\end{array}$ & $\mathrm{N} / \mathrm{A}$ & Probably compatible \\
\hline Interferon- $\beta$ & Negligible in 6 women [61] & $0.006 \%[61]$ & Compatible \\
\hline$[17,18]$ & $\begin{array}{l}\text { Low likelihood as large MW } \\
(22,500 \mathrm{Da})\end{array}$ & & $\begin{array}{l}\text { EMA: IFN-beta 1a can be used while } \\
\text { breastfeeding [17] }\end{array}$ \\
\hline \multicolumn{4}{|l|}{ Oral } \\
\hline $\begin{array}{l}\text { Dimethyl } \\
\text { fumarate }[19, \\
\text { 20] }\end{array}$ & $\begin{array}{l}\text { Unknown. Likely due to low MW } \\
\text { (129 Da) of active metabolite } \\
\text { (MMF). Rapid metabolism and high } \\
\text { V }_{\text {D }} \text { may decrease transfer }\end{array}$ & N/A & Not compatible \\
\hline $\begin{array}{l}\text { Diroximel } \\
\text { fumarate [22] }\end{array}$ & $\begin{array}{l}\text { Unknown. Likely due to low MW } \\
\text { (129 Da) of active metabolite } \\
\text { (MMF), although rapid metabolism } \\
\text { and high } V_{D} \text { may decrease transfer }\end{array}$ & $\mathrm{N} / \mathrm{A}$ & Not compatible \\
\hline $\begin{array}{l}\text { Fingolimod } \\
{[23,24]}\end{array}$ & $\begin{array}{l}\text { Unknown. Likely due to low MW } \\
(344 \mathrm{Da}) \text { and long } 1 / 2 \text { although } \\
\text { high protein binding may decrease } \\
\text { transfer }\end{array}$ & $\mathrm{N} / \mathrm{A}$ & Not compatible \\
\hline $\begin{array}{l}\text { Siponimod } \\
{[26]}\end{array}$ & $\begin{array}{l}\text { Unknown. Likely due to long } \mathrm{t} 1 / 2 \\
\text { although moderate MW (1149 Da) } \\
\text { and high protein binding may de- } \\
\text { crease transfer }\end{array}$ & $\mathrm{N} / \mathrm{A}$ & Not compatible \\
\hline $\begin{array}{l}\text { Cladribine } \\
{[27,28]}\end{array}$ & $\begin{array}{l}\text { Unknown. Likely due to low MW } \\
\text { ( } 286 \mathrm{Da}) \text { and low protein binding, } \\
\text { although high } \mathrm{V}_{\mathrm{D}} \text { may decrease } \\
\text { transfer }\end{array}$ & N/A & $\begin{array}{l}\text { Not compatible } \\
\text { Contraindicated for } 7 \text { (EMA) or } 10 \\
\text { (FDA) days after last dose }\end{array}$ \\
\hline $\begin{array}{l}\text { Teriflunomide } \\
{[30,31]}\end{array}$ & $\begin{array}{l}\text { Unknown. Likely due to low MW } \\
(270 \mathrm{Da}) \text { and long } \mathrm{t} 1 / 2 \text { although } \\
\text { high protein binding may decrease } \\
\text { transfer }\end{array}$ & $\mathrm{N} / \mathrm{A}$ & $\begin{array}{l}\text { Not compatible } \\
\text { Contraindicated (EMA)/not } \\
\text { recommended (FDA) }\end{array}$ \\
\hline \multicolumn{4}{|l|}{ Infusion } \\
\hline $\begin{array}{l}\text { Natalizumab } \\
{[106,107]}\end{array}$ & Low in 10 women $[40 \bullet \bullet, 65,67,112]$ & $\begin{array}{l}\text { 1.7-5.3\% with } \\
\text { cumulative effects } \\
\text { of monthly dosing } \\
\text { expected }(n=1) \\
\text { [67] } \\
\text { Maximum } 0.5 \%(n=3) \\
{[40 \bullet \bullet \text { ] }}\end{array}$ & $\begin{array}{l}\text { Probably compatible } \\
\text { Note: natalizumab not detectable in } \\
\text { infant blood while breastfeeding }(n=2) \\
\text { and no anemia in infants exposed only } \\
\text { through breastmilk }(2 / 2)[40 \bullet \bullet]\end{array}$ \\
\hline $\begin{array}{l}\text { Rituximab } \\
{[41,42]}\end{array}$ & Low in 10 women $[66 \bullet \bullet, 113]$ & $\begin{array}{l}0.08 \% \text { (range } \\
0.06-0.10) ; \\
\text { maximum } 0.33 \% \\
{[66 \bullet \bullet]}\end{array}$ & $\begin{array}{l}\text { Probably compatible } \\
\text { Note: normal infant B-cells while } \\
\text { breastfeeding }(3 / 3)[40 \bullet \bullet]\end{array}$ \\
\hline & & N/A & Probably compatible \\
\hline
\end{tabular}


Table 2. (Continued)

\begin{tabular}{|c|c|c|c|}
\hline DMT & Transfer to breastmilk & $\begin{array}{l}\text { Relative infant } \\
\text { dose (RID) }\end{array}$ & $\begin{array}{l}\text { Recommendation for use while } \\
\text { breastfeeding* }\end{array}$ \\
\hline $\begin{array}{l}\text { Ocrelizumab } \\
{[35,34]}\end{array}$ & $\begin{array}{l}\text { Unknown. Likely low as large MW and } \\
\text { limited IgG1 transfer to breastmilk }\end{array}$ & & $\begin{array}{l}\text { Note: normal infant B-cells while } \\
\text { breastfeeding }(2 / 2)[40 \bullet \bullet]\end{array}$ \\
\hline $\begin{array}{l}\text { Alemtuzumab } \\
{[45,46]}\end{array}$ & $\begin{array}{l}\text { Unknown. Likely low as large MW and } \\
\text { limited IgG1 transfer to breastmilk }\end{array}$ & N/A & $\begin{array}{l}\text { Probably compatible } \\
\text { EMA: breastfeeding } 4 \text { months after last } \\
\text { dose safe }\end{array}$ \\
\hline
\end{tabular}

of concern if there are delays in conception or need for fertility assistance, and in the peripartum period (final weeks of pregnancy until the year post-delivery) since peripartum depression affects up to 1 in 5 women in the general population and could be exacerbated by prior episodes of depression $[79,80]$, which is common in MS. [81] Social support may include help caring for the newborn (e.g., providing night-time feeds), with household tasks, or with work reassignments. When possible, contributing factors should be assessed prior to initiation of additional medications, but medications are commonly used during pregnancy and should be prescribed in concert with the obstetrical provider and/or pediatrician.

\section{Impact of COVID-19 on pregnancy and implications for MS pregnancy}

Concerns around infection with SARS-CoV-2, the novel coronavirus leading to COVID-19 infection, are particularly marked, both for people with MS and pregnant women. To date, MS itself does not appear to increase risk or severity of COVID-19 infection [82], although there is a suggestion that some DMTs such as anti-CD20 therapies may increase risk of severe COVID-19 based on data available in pre-print form from Italy (https://papers.ssrn.com/sol3/ papers.cfm?abstract_id=3631244), and data on lymphocyte depleting agents such as alemtuzumab and cladribine are lacking. Additionally, the immunotolerant state of pregnancy could influence response to viral infections. While to date pregnant women do not appear more likely to contract COVID-19 infection, pregnant women with obesity or comorbidities are at risk for severe COVID-19 infection which may require urgent delivery for maternal respiratory compromise [83, 84]. A systematic review of case reports and series reported generally good outcomes for mothers with COVID-19 and their neonates, although found high rates of preterm birth ( $39 \%)$ and cesarean section (up to $96 \%$ ) in women with COVID-19 infection, although most were elective interventions [85•]. Additionally, there may be a cohort of minimally symptomatic, or even asymptomatic individuals who carry the SARS-CoV-2 virus, some of whom may be pregnant [ $86 \bullet]$. Case fatality rates in pregnant women with SARS, a prior novel coronavirus infection, were estimated to be up to $25 \%$; fortunately, this mortality pattern has not been replicated thus far in the COVID-19 pandemic. More research into the outcomes of COVID-19 infection 
in pregnancy and MS is required; to date, we are not aware of our own or published cases.

There is also a theoretical risk of vertical transmission of the virus antenatally or intrapartum, as ACE2 receptors are expressed in the placenta. The proportion of pregnancies affected and significance to the neonate, particularly of early exposure, are not known currently, given the recency of the pandemic. A small number of neonates have tested positive for the SARS-CoV-2 virus shortly after delivery, but it is not known when the neonate was infected. In a series of 6 women with COVID-19 infection in the third trimester, no viral isolates were found in amniotic fluid, cord blood, breastmilk, or neonatal throat swabs, suggesting against intrauterine transmission [87]. The SARS-CoV-2 virus has been detected in breastmilk of a single infected woman [88]; other studies of infected women have not detected the virus in breastmilk [89]. Symptomatic women should wear a facemask and wash their hands prior to breastfeeding to minimize potential droplet transmission. Similar to other viral infections, antiSARS-CoV-2 antibodies may be transferred to the infant via breastmilk, but this has not been confirmed.

During the COVID-19 pandemic, DMTs should be discussed prior to pregnancy as routinely done. Many pregnant women with MS will remain off DMT during pregnancy, while continuation of DMTs that may be used during pregnancy such as glatiramer acetate, interferon-betas, and natalizumab have not generally been altered due to the current pandemic. Use of lymphocytedepleting agents prior to pregnancy should be considered in the context of guidelines, such as those of the Multiple Sclerosis International Federation (see below) that are regularly updated as additional data emerges, given these may increase risk and severity of COVID-19 infection.

The COVID-19 pandemic has presented an unprecedented challenge for both obstetrical and neurological care of patients with MS. While we await data that could guide specific recommendations in MS due to both pregnancyrelated and DMT-related immunological changes and implications on disease activity and pregnancy outcomes, it is critical to adhere to general recommendations and follow updated guidance regarding obstetrical (https://www.acog. org/en/Topics/COVID-19; https://www.cdc.gov/coronavirus/2019-ncov/index. html) and MS care (https://www.msif.org/news/2020/02/10/the-coronavirusand-ms-what-you-need-to-know/). As with the general population, pregnant women with MS should follow appropriate social distancing and/or shielding measures depending on their immunosuppressant exposure and comorbidities. They should be advised to maintain regular contact with obstetric services to ensure adequate antenatal care.

\section{Conclusion}

Ideally, family planning counseling should begin prior to conception to ensure strategies are in place to protect the mother's health and wellbeing, as well as that of the fetus and eventually neonate. Pregnancy planning should consider maternal disease activity, risk of disease reactivation with therapy withdrawal, postpartum relapse risk, and breastfeeding plans. Breastfeeding may be protective against postpartum relapses; however, in women with active disease, concomitant use of certain DMTs should be considered. Emerging data 
demonstrate that injectable and monoclonal antibody therapies may be considered while breastfeeding. Whole-patient care involves evaluation and treatment of ambulatory, bladder, and mood symptoms, with non-pharmacologic approaches when possible. Given rapidly evolving data in MS therapy management in pregnancy, it is important to keep up-to-date when advising women with MS around pregnancy, particularly during the current COVID-19 pandemic.

\section{Compliance with Ethical Standards}

\section{Conflict of Interest}

Kristen M Krysko was funded by a Sylvia Lawry Physician Fellowship through the National Multiple Sclerosis Society (FP-1605-08753 (Krysko)). She also had fellowship funding through Biogen.

Riley Bove is funded by a Harry Weaver Scholarship through the National Multiple Sclerosis Society. She has received recent research support from the National Multiple Sclerosis Society, the California Initiative to Advance Precision Medicine, the Hilton Foundation, the Sherak Foundation, the Weill Innovation Fund, the UCSF CTSI RAP program, and Akili Interactive. She has received consulting fees from Alexion, Biogen, EMD Serono, Genzyme Sanofi, Novartis, and Roche Genentech.

Ruth Dobson works within the PNU, which is funded by Barts Charity. She receives grant support from the UK MS Society, Horne Family Charitable Trust, Biogen, Celgene, and Merck. She has received honoraria for Advisory boards and/or educational activities from Biogen, Teva, Sanofi, Merck, and Roche.

Vilija Jokubaitis is funded by an MS Research Australia Fellowship (16-0206). She receives project grant support from the National Health and Medical Research Council (NHMRC) of Australia (GNT1156519) and MS Research Australia (18-0424; 19-0665). She has received honoraria from Biogen and Roche for non-promotional educational activities, and conference travel support from Merck and Roche.

Kerstin Hellwig receives grant support from the Innovation Fund of the Federal Joint Committee. She has also received consultant and speaker honoraria and grant support from Bayer, Biogen, Merck, Novartis, Sanofi Genzyme, Roche, and Teva.

\section{Human and Animal Rights}

All reported studies/experiments with human or animal subjects performed by the authors have been previously published and complied with all applicable ethical standards (including the Helsinki declaration and its amendments, institutional/national research committee standards, and international/national/institutional guidelines).

\section{References and Recommended Reading}

Papers of particular interest, published recently, have been highlighted as:

- Of importance

$\bullet$ Of major importance

1. Thompson AJ, Banwell BL, Barkhof F, Carroll WM, Coetzee T, Comi G, et al. Diagnosis of multiple sclerosis: 2017 revisions of the McDonald criteria. Lancet Neurol. 2018;17:162-73.

2. Koch-Henriksen N, Thygesen LC, Stenager E, Laursen B, Magyari M. Incidence of MS has increased markedly over six decades in Denmark particularly with late onset and in women. Neurology. 2018;90(22):e1954e63.

3. Trojano M, Lucchese G, Graziano G, Taylor BV, Simpson S Jr, Lepore V, et al. Geographical variations in sex ratio trends over time in multiple sclerosis. PLoS One. 2012;7(10):e48078. 
4. Confavreux C, Hutchinson M, Hours MM, CortinovisTourniaire P, Moreau T. Rate of pregnancy-related relapse in multiple sclerosis. Pregnancy in multiple sclerosis group. N Engl J Med. 1998;339(5):285-91.

5. Hughes SE, Spelman T, Gray OM, Boz C, Trojano M, Lugaresi A, et al. Predictors and dynamics of postpartum relapses in women with multiple sclerosis. Mult Scler. 2014;20(6):739-46.

6. Houtchens MK, Edwards NC, Phillips AL. Relapses and disease-modifying drug treatment in pregnancy and live birth in US women with MS. Neurology. 2018;91(17):e1570-e8.

7. Bsteh G, Algrang L, Hegen H, Auer M, Wurth S, Di Pauli $\mathrm{F}$, et al. Pregnancy and multiple sclerosis in the DMT era: a cohort study in Western Austria. Mult Scler. 2020;26:69-78.

8. $\quad$ Langer-Gould A, Smith JB, Albers KB, Xiang AH, Wu J, Kerezsi EH, et al. Pregnancy-related relapses and breastfeeding in a contemporary multiple sclerosis cohort. Neurology. 2020;94(18):1-e11.

A contemporary cohort study suggesting that postpartum MS relapse risk may not be elevated in women with milder MS exclusively breastfeeding.

9. Jokubaitis VG, Spelman T, Kalincik T, Lorscheider J, Havrdova E, Horakova D, et al. Predictors of long-term disability accrual in relapse-onset multiple sclerosis. Ann Neurol. 2016;80(1):89-100.

10. Zuluaga MI, Otero-Romero S, Rovira A, Perez-Hoyos S, Arrambide G, Negrotto L, et al. Menarche, pregnancies, and breastfeeding do not modify long-term prognosis in multiple sclerosis. Neurology. 2019;92(13):e1507e16.

11. Portaccio E, Ghezzi A, Hakiki B, Sturchio A, Martinelli $\mathrm{V}$, Moiola L, et al. Postpartum relapses increase the risk of disability progression in multiple sclerosis: the role of disease modifying drugs. J Neurol Neurosurg Psychiatry. 2014;85(8):845-50.

12. De Angelis F, John NA, Brownlee WJ. Diseasemodifying therapies for multiple sclerosis. BMJ. 2018;363:k4674.

13. Montalban X, Hauser SL, Kappos L, Arnold DL, Bar-Or A, Comi G, et al. Ocrelizumab versus placebo in primary progressive multiple sclerosis. $\mathrm{N}$ Engl J Med. 2017;376(3):209-20.

14. Alroughani R, Alowayesh MS, Ahmed SF, Behbehani R, Al-Hashel J. Relapse occurrence in women with multiple sclerosis during pregnancy in the new treatment era. Neurology. 2018;90(10):e840-e6.

Important demonstration of increased risk of relapse during pregnancy in women discontinuing natalizumab and fingolimod.

15. Nguyen AL, Havrdova EK, Horakova D, Izquierdo G, Kalincik T, van der Walt A, et al. Incidence of pregnancy and disease-modifying therapy exposure trends in women with multiple sclerosis: a contemporary cohort study. Mult Scler Relat Disord. 2019;28:235-43.

16. European Medicines Agency (EMA). Evaluation of medicines for human use. Guidelines on risk assessment of medical products on human reproduction and lactation: from data to labeling. http://www.ema. europa.eu/docs/en_GB/document_library/Scientific_ guideline/2009/09/WC500003307.pdf London 2008. Accessed January 1, 2020.

17. EMA. Avonex (interferon beta 1 a) - EPAR summary of product characteristics 2019. https://www.ema.europa. $\mathrm{eu} / \mathrm{en} /$ documents/product-information/avonex-eparproduct-information_en.pdf. Accessed Dec 4, 2019.

18. Biogen. Avonex (interferon beta-1A) [package insert]. U.S. Food and Drug Administration website. https:// www.accessdata.fda.gov/drugsatfda_docs/label/2020/ 103628s5263lbl.pdf. Revised March 2020. Accessed April 22, 2020.

19. EMA. Tecfidera (dimethyl fumarate) - EPAR summary of product characteristics 2019. https://www.ema. europa.eu/en/medicines/human/EPAR/tecfidera.

Accessed Dec 4, 2019.

20. Biogen. Tecfidera (dimethyl fumarate) [package insert]. U.S. Food and Drug Administration website. https:// www.accessdata.fda.gov/drugsatfda_docs/label/2019/ 204063s024lbl.pdf. Revised July 2019. Accessed Dec 4, 2019.

21. Hellwig K. An international registry tracking pregnancy outcomes in women treated with dimethyl fumarate. Stockholm, Sweden: ECTRIMS; 2019.

22. Alkermes. Vumerity (diroximel fumarate) [package insert]. U.S. Food and Drug Administration website. https://www.accessdata.fda.gov/drugsatfda_docs/ label/2019/211855s000lbl.pdf. Revised Oct 2019. Accessed Dec 4, 2019.

23. EMA. Gilenya (fingolimod) - EPAR summary of product characteristics 2019. https://www.ema.europa.eu/ en/documents/product-information/gilenya-eparproduct-information_en.pdf. Accessed Dec 4, 2019.

24. Novartis. Gilenya (fingolimod) [package insert]. U.S. Food and Drug Administration website. https://www. accessdata.fda.gov/drugsatfda_docs/label/2019/ 022527s029s030lbl.pdf. Revised Aug 2019. Accessed Dec 4, 2019.

25. Hellwig K. Effect of fingolimod on pregnancy outcomes in patients with multiple sclerosis. Stockholm, Sweden: ECTRIMS; 2019.

26. Novartis. Mayzent (siponimod) [package insert]. U.S. Food and Drug Administration website. https://www. accessdata.fda.gov/drugsatfda_docs/label/2019/ 022527s029s030lbl.pdf. Revised Mar 2019. Accessed Dec 4, 2019.

27. EMA. Mavenclad (cladribine) - EPAR summary of product characteristics 2019. https://www.ema.europa. $\mathrm{eu} / \mathrm{en} /$ documents/product-information/mavencladepar-product-information_en.pdf. Accessed Dec 4, 2019.

28. EMD Serono. Mavenclad (cladribine) [package insert]. U.S. Food and Drug Administration https://www. accessdata.fda.gov/drugsatfda_docs/label/2019/ 022561s000lbl.pdf. Revised Mar 2019. Accessed Dec 4, 2019.

29. Galazka A, Nolting A, Cook S, Leist T, Comi G, Montalban $\mathrm{X}$, et al. Pregnancy outcomes during the clinical 
development programme of cladribine in multiple sclerosis (MS): an integrated analysis of safety for all exposed patients. Paris, France: ECTRIMS; 2017.

30. EMA. Aubagio (teriflunomide) - EPAR summary of product characteristics 2019. https://www.ema.europa. $\mathrm{eu} / \mathrm{en} /$ documents/product-information/aubagio-eparproduct-information_en.pdf. Accessed Dec 4, 2019.

31. Sanofi Aventis US. Aubagio (teriflunomide) [package insert]. U.S. Food and Drug Administration https:// www.accessdata.fda.gov/drugsatfda_docs/label/2019/ 202992s008lbl.pdf. Revised Sept 2019. Accessed Dec 4, 2019.

32. Vukusic S, Coyle PK, Jurgensen S, Truffinet P, Benamor M, Afsar S, et al. Pregnancy outcomes in patients with multiple sclerosis treated with teriflunomide: clinical study data and 5 years of post-marketing experience. Mult Scler. 2019;10:1352458519843055.

33. DeSesso JM, Williams AL, Ahuja A, Bowman CJ, Hurtt ME. The placenta, transfer of immunoglobulins, and safety assessment of biopharmaceuticals in pregnancy. Crit Rev Toxicol. 2012;42(3):185-210.

34. EMA. Ocrevus (ocrelizumab) - EPAR summary of product characteristics 2019. https://www.ema.europa eu/en/documents/product-information/ocrevus-eparproduct-information_en.pdf. Accessed Dec 10, 2019.

35. Genentech. Ocrevus (ocrelizumab) [package insert]. U.S. Food and Drug Administration. https://www. accessdata.fda.gov/drugsatfda_docs/label/2019/ 761053s018lbl.pdf. Revised July 2019. Accessed Dec 10, 2019.

36. Das G, Damotte V, Gelfand JM, Bevan C, Cree BAC, Do $\mathrm{L}$, et al. Rituximab before and during pregnancy: a systematic review, and a case series in MS and NMOSD. Neurol Neuroimmunol Neuroinflamm.

2018;5(3):e453.

37. Oreja-Guevara C, Wray S, Buffels R, Zecevic D, Vukusic $\mathrm{S}$. Pregnancy outcomes in patients treated with ocrelizumab. Stockholm, Sweden: ECTRIMS; 2019.

38.• Smith JB, Hellwig K, Fink K, Lyell DJ, Piehl F, LangerGould A. Rituximab, MS, and pregnancy. Neurol Neuroimmunol Neuroinflamm. 2020;7(4):e734.

An important cohort study demonstrating rituximab use before pregnancy led to little MS disease activity, and no increase in adverse pregnancy outcomes.

39. Chakravarty EF, Murray ER, Kelman A, Farmer P. Pregnancy outcomes after maternal exposure to rituximab. Blood. 2011;117(5):1499-506.

40.• Ciplea AI, Langer-Gould A, de Vries A, Schaap T, Thiel $\mathrm{S}$, Ringelstein $\mathrm{M}$, et al. Monoclonal antibody treatment during pregnancy and/or lactation in women with MS or neuromyelitis optica spectrum disorder. Neurol Neuroimmunol Neuroinflamm. 2020;7(4):e723.

Important study showing no negative effect on infant health of possible breastmilk exposure to monoclonal antibody therapies.

41. Genentech. Rituxan (rituximab) [package insert]. U.S. Food and Drug Administration. https://www. accessdata.fda.gov/scripts/cder/daf/index.cfm?event=
overview.process\&ApplNo=103705. Revised

Sept 2019. Accessed Dec 10, 2019.

42. EMA. Rixathon (rituximab) - EPAR summary of product characteristics 2019. https://www.ema.europa.eu/ en/documents/product-information/rixathon-eparproduct-information_en.pdf. Accessed Dec 10, 2019.

43. Langer-Gould AM. Pregnancy and family planning in multiple sclerosis. Continuum (Minneap Minn). 2019;25(3):773-92.

A comprehensive review of pregnancy planning in MS.

44. Mao-Draayer Y, Thiel S, Mills EA, Chitnis T, Fabian M, Katz Sand I, et al. Neuromyelitis optica spectrum disorders and pregnancy: therapeutic considerations. Nat Rev Neurol. 2020;16(3):154-70.

45. Genzyme. Lemtrada (alemtuzumab) [package insert]. U.S. Food and Drug Administration. https://www. accessdata.fda.gov/drugsatfda_docs/label/2019/ 103948s5169s5170lbl.pdf. Revised Oct 2019.

Accessed Dec 10, 2019.

46. EMA. Lemtrada (alemtuzumab) - EPAR summary of product characteristics 2019. https://www.ema.europa. eu/en/documents/product-information/lemtradaepar-product-information_en.pdf. Accessed Dec 10, 2019.

47. Hellwig K, Gold R. Immune reconstitution inflammatory syndrome after withdrawal of natalizumab? Neurology. 2011;76(15):1362-3 author reply.

48. De Giglio L, Gasperini C, Tortorella C, Trojano M, Pozzilli C. Natalizumab discontinuation and disease restart in pregnancy: a case series. Acta Neurol Scand. 2015;131(5):336-40.

49. Portaccio E, Moiola L, Martinelli V, Annovazzi P, Ghezzi A, Zaffaroni M, et al. Pregnancy decisionmaking in women with multiple sclerosis treated with natalizumab: II: maternal risks. Neurology.

2018;90(10):e832-e9. Important demonstration of increased risk of relapses in pregnancy in those discontinuing natalizumab.

50. Haghikia A, Langer-Gould A, Rellensmann G, Schneider H, Tenenbaum T, Elias-Hamp B, et al. Natalizumab use during the third trimester of pregnancy. JAMA Neurol. 2014;71(7):891-5.

51. Landi D, Portaccio E, Bovis F, Annovazzi P, Brescia Morra V, Bucello S, et al. Continuation of natalizumab versus interruption is associated with lower risk of relapses during pregnancy and postpartum in women with MS. Mult Scler. 2019;25:890-938.

52. Park-Wyllie L, Mazzotta P, Pastuszak A, Moretti ME, Beique L, Hunnisett L, et al. Birth defects after maternal exposure to corticosteroids: prospective cohort study and meta-analysis of epidemiological studies. Teratology. 2000;62(6):385-92.

53. Räikkönen K, Gissler M, Kajantie E. Associations between maternal antenatal corticosteroid treatment and mental and behavioral disorders in children. JAMA. 2020;323(19):1924-33.

54. Cox JL, Koepsell SA, Shunkwiler SM. Therapeutic plasma exchange and pregnancy: a case report and 
guidelines for performing plasma exchange in a pregnant patient. J Clin Apher. 2017;32(3):191-5.

55. Breastfeeding SO. Breastfeeding and the use of human milk. Pediatrics. 2012;129(3):e827-e41.

56. Krysko KM, Rutatangwa A, Graves J, Lazar A, Waubant E. Association between breastfeeding and postpartum multiple sclerosis relapses: a systematic review and meta-analysis. JAMA Neurol. 2020;77(3):327-38.

A comprehensive systematic review and meta-analysis summarizing the protective effect of breastfeeding on postpartum MS relapses.

57. Hellwig K, Rockhoff $\mathrm{M}$, Herbstritt $\mathrm{S}$, Borisow N, Haghikia A, Elias-Hamp B, et al. Exclusive breastfeeding and the effect on postpartum multiple sclerosis relapses. JAMA Neurol. 2015;72(10):1132-8.

58. Wang J, Johnson T, Sahin L, Tassinari MS, Anderson PO, Baker TE, et al. Evaluation of the safety of drugs and biological products used during lactation: workshop summary. Clin Pharmacol Ther. 2017;101(6):736-44.

59. Bennett PN. Drugs and human lactation: a comprehensive guide to the content and consequences of drugs, micronutrients, radiopharmaceuticals and environmental and occupational chemicals in human milk. Second ed. Amsterdam, The Netherlands: Elsevier; 1996

60. Teva Pharms USA. Copaxone (glatiramer acetate) [package insert]. U.S. Food and Drug Administration. https://www.accessdata.fda.gov/scripts/cder/daf/index. $\mathrm{cfm}$ ? event=overview.process \&ApplNo=020622. Revised July 2019. Accessed Dec 4, 2019.

61. Hale TW, A.A. S, Baker TE. Transfer of interferon beta1a into human breastmilk. Breastfeed Med. 2012;7(2):123-5.

62. Ciplea AI, Langer-Gould A, Stahl A, Thiel S, QueisserWahrendorf A, Gold R, et al. Safety of potential breast milk exposure to IFN- $\beta$ or glatiramer acetate: one-year infant outcomes. Neurol Neuroimmunol Neuroinflamm. 2020;7(4):e757.

63. LaHue SC, Anderson A, Krysko KM, Rutatangwa A, Dorsey M, Hale TW, et al. Transfer of monoclonal antibodies into breastmilk in neurologic and nonneurologic diseases. Neurol Neuroimmunol Neuroinflamm. 2020;7(4):e769.

A narrative review of monoclonal antibody therapy use while breastfeeding in several diseases.

64. Giragossian C, Clark T, Piche-Nicholas N, Bowman CJ. Neonatal Fc receptor and its role in the absorption, distribution, metabolism and excretion of immunoglobulin G-based biotherapeutics. Curr Drug Metab. 2013;14(7):764-90.

65. Matro R, Martin CF, Wolf D, Shah SA, Mahadevan U. Exposure concentrations of infants breastfed by women receiving biologic therapies for inflammatory bowel diseases and effects of breastfeeding on infections and development. Gastroenterology. 2018;155(3):696704.

66.• Krysko KM, LaHue SC, Anderson A, Rutatangwa A, Rowles W, Schubert RD, et al. Minimal breast milk transfer of rituximab, a monoclonal antibody used in neurological conditions. Neurol Neuroimmunol Neuroinflamm. 2020;7(1):e637.

An important study demonstrating little transfer of rituximab into breastmilk.

67. Baker TE, Cooper SD, Kessler L, Hale TW. Transfer of natalizumab into breast milk in a mother with multiple sclerosis. J Hum Lact. 2015;31(2):233-6.

68. Boz C, Terzi M, Zengin Karahan S, Sen S, Sarac Y, Emrah MM. Safety of IV pulse methylprednisolone therapy during breastfeeding in patients with multiple sclerosis. Mult Scler. 2018;24(9):1205-11.

69. Cooper SD, Felkins K, Baker TE, Hale TW. Transfer of methylprednisolone into breast milk in a mother with multiple sclerosis. J Hum Lact. 2015;31(2):237-9.

70. de Seze J, Chapelotte M, Delalande S, Ferriby D, Stojkovic T, Vermersch P. Intravenous corticosteroids in the postpartum period for reduction of acute exacerbations in multiple sclerosis. Mult Scler. 2004;10(5):596-7.

71. Rosa GR, O'Brien AT, Nogueira EAG, Carvalho VM, Paz $\mathrm{SC}$, Fragoso YD. There is no benefit in the use of postnatal intravenous immunoglobulin for the prevention of relapses of multiple sclerosis: findings from a systematic review and meta-analysis. Arq Neuropsiquiatr. 2018;76(6):361-6.

72. Block VJ, Bove R, Zhao C, Garcha P, Graves J, Romeo $\mathrm{AR}$, et al. Association of continuous assessment of step count by remote monitoring with disability progression among adults with multiple sclerosis. JAMA Netw Open. 2019;2(3):e190570.

73. Physical activity and exercise during pregnancy and the postpartum period: ACOG committee opinion, Number 804. Obstet Gynecol. 2020;135(4):e178-e88.

Physical activity and exercise recommendations during pregnancy and postpartum.

74. de Sèze M, Gamé X. Multiple sclerosis and pelviperineology: urinary and sexual dysfunctions and pregnancy. Prog Urol. 2014;24(8):483-94.

75. Durufle A, Petrilli S, Nicolas B, Robineau S, Guille F, Edan G, et al. Effects of pregnancy and child birth on urinary symptoms and urodynamics in women with multiple sclerosis. Int Urogynecol J Pelvic Floor Dysfunct. 2006;17(4):352-5.

76. de Sèze M, Ruffion A, Denys P, Joseph PA, PerrouinVerbe $\mathrm{B}$. The neurogenic bladder in multiple sclerosis: review of the literature and proposal of management guidelines. Mult Scler. 2007;13(7):915-28.

77. Mazor-Dray E, Levy A, Schlaeffer F, Sheiner E. Maternal urinary tract infection: is it independently associated with adverse pregnancy outcome? J Matern Fetal Neonatal Med. 2009;22(2):124-8.

78. Payne D, McPherson KM. Becoming mothers. Multiple sclerosis and motherhood: a qualitative study. Disabil Rehabil. 2010;32(8):629-38.

79. Jones I, Shakespeare J. Postnatal depression. BMJ. 2014;349:g4500.

80. Langan R, Goodbred AJ. Identification and Management of Peripartum Depression. Am Fam Physician. 2016;93(10):852-8. 
81. Razaz N, Tremlett H, Marrie RA, Joseph KS. Peripartum depression in parents with multiple sclerosis and psychiatric disorders in children. Mult Scler.

2016;22(14):1830-40.

82. Sormani MP. An Italian programme for COVID-19 infection in multiple sclerosis. Lancet Neurol. 2020;19(6):481-2.

83. Lokken EM, Walker CL, Delaney S, Kachikis A, Kretzer NM, Erickson A, et al. Clinical characteristics of 46 pregnant women with a SARS-CoV-2 infection in Washington state. Am J Obstet Gynecol. 2020;223:911.e1-911.e14.

84. Savasi VM, Parisi F, Patanè L, Ferrazzi E, Frigerio L, Pellegrino A, et al. Clinical findings and disease severity in hospitalized pregnant women with coronavirus disease 2019 (COVID-19). Obstet Gynecol. 2020;136:252-8.

85. Della Gatta AN, Rizzo R, Pilu G, Simonazzi G. Coronavirus disease 2019 during pregnancy: a systematic review of reported cases. Am J Obstet Gynecol. 2020;223(1):36-41.

Systematic review of pregnancy outcomes with COVID-19.

86. Breslin N, Baptiste C, Gyamfi-Bannerman C, Miller R, Martinez R, Bernstein K, et al. COVID-19 infection among asymptomatic and symptomatic pregnant women: two weeks of confirmed presentations to an affiliated pair of New York City hospitals. Am J Obstet Gynecol MFM. 2020;2(2):100118.

Demonstration of COVID-19 infection in asymptomatic and symptomatic pregnant women.

87. Chen H, Guo J, Wang C, Luo F, Yu X, Zhang W, et al. Clinical characteristics and intrauterine vertical transmission potential of COVID-19 infection in nine pregnant women: a retrospective review of medical records. Lancet. 2020;395(10226):809-15.

88. Groß R, Conzelmann C, Müller JA, Stenger S, Steinhart $\mathrm{K}$, Kirchhoff F, et al. Detection of SARS-CoV-2 in human breastmilk. Lancet. 2020;395:1757-8.

89. Lackey KA, Pace RM, Williams JE, Bode L, Donovan SM, Järvinen KM et al. SARS-CoV-2 and human milk: what is the evidence? medRxiv.

2020:2020.04.07.20056812.

90. Giannini M, Portaccio E, Ghezzi A, Hakiki B, Pasto L, Razzolini L, et al. Pregnancy and fetal outcomes after glatiramer acetate exposure in patients with multiple sclerosis: a prospective observational multicentric study. BMC Neurol. 2012;12:124.

91. Hellwig K, Haghikia A, Rockhoff M, Gold R. Multiple sclerosis and pregnancy: experience from a nationwide database in Germany. Ther Adv Neurol Disord. 2012;5(5):247-53.

92. Herbstritt S, Langer-Gould A, Rockhoff M, Haghikia A, Queisser-Wahrendorf A, Gold R, et al. Glatiramer acetate during early pregnancy: a prospective cohort study. Mult Scler. 2016;22(6):810-6.

93. Lu E, Wang BW, Guimond C, Synnes A, Sadovnick D, Tremlett H. Disease-modifying drugs for multiple sclerosis in pregnancy: a systematic review. Neurology. 2012;79(11):1130-5.
94. Salminen HJ, Leggett H, Boggild M. Glatiramer acetate exposure in pregnancy: preliminary safety and birth outcomes. J Neurol. 2010;257(12):2020-3.

95. Hellwig K, Gold R. Glatiramer acetate and interferonbeta throughout gestation and postpartum in women with multiple sclerosis. J Neurol. 2011;258(3):502-3.

96. Hellwig K, Neudorfer O, Melamed-Gal S, Qassem S, Baruch P. Pregnancy outcomes in patients with multiple sclerosis and exposure to branded glatiramer acetate during all three trimesters. Paris, France: ECTRIMSACTRIMS; 2017.

97. Serono Inc. Rebif (interferon beta-1A) [package insert]. U.S. Food and Drug Administration website. https:// www.accessdata.fda.gov/drugsatfda_docs/label/2019/ 103780s5204lbl.pdf. Revised July 2019. Accessed Jan 1, 2020.

98. Bayer Healthcare. Betaseron (interferon beta-1B) [package insert]. U.S. Food and Drug Administration website. https://www.accessdata.fda.gov/drugsatfda_ docs/label/2019/103471s5195lbl.pdf. Revised August 2019. Accessed Jan 1, 2020.

99. Biogen Idec. Plegridy (peginterferon beta-1A) [package insert]. U.S. Food and Drug Administration website. https://www.accessdata.fda.gov/drugsatfda_docs/ label/2019/125499s019lbl.pdf. Revised July 2019. Accessed Jan 1, 2020.

100. Hellwig K, Haghikia A, Gold R. Parenthood and immunomodulation in patients with multiple sclerosis. J Neurol. 2010;257(4):580-3.

101. Thiel S, Langer-Gould A, Rockhoff M, Haghikia A, Queisser-Wahrendorf A, Gold R, et al. Interferon-beta exposure during first trimester is safe in women with multiple sclerosis-a prospective cohort study from the German multiple sclerosis and pregnancy registry. Mult Scler. 2016;22(6):801-9.

102. Sandberg-Wollheim M, Alteri E, Moraga MS, Kornmann G. Pregnancy outcomes in multiple sclerosis following subcutaneous interferon beta-1a therapy. Mult Scler. 2011;17(4):423-30.

103. Hellwig K, Duarte Caron F, Wicklein EM, Bhatti A, Adamo A. Pregnancy outcomes from the global pharmacovigilance database on interferon beta-1b exposure. Ther Adv Neurol Disord. 2020;13:1756286420910310.

104. Hellwig K, Geissbuehler Y, Sabido M, Popescu C, Adamo A, Klinger J, et al. Pregnancy outcomes in interferon-beta-exposed patients with multiple sclerosis: results from the European Interferon-beta Pregnancy Registry. J Neurol. 2020;267:1715-23.

105. Hellwig K, Thiel S, Ciplea AI, Galazka A, Schick R, Hubschen M. Pregnancy of MS patients treated with cladribine tablets. Toronto, Canada: AAN; 2020.

106. Biogen. Tysabri (natalizumab) [package insert]. U.S. Food and Drug Administration. https://www. accessdata.fda.gov/drugsatfda_docs/label/2019/ 125104s966lbl.pdf. Revised Aug 2019. Accessed Dec 10, 2019.

107. EMA. Tysabri (natalizumab) - EPAR summary of product characteristics 2019. https://www.ema. 
europa.eu/en/documents/product-information/ tysabri-epar-product-information_en.pdf. Accessed Dec 10, 2019.

108. Portaccio E, Annovazzi P, Ghezzi A, Zaffaroni M, Moiola L, Martinelli V, et al. Pregnancy decisionmaking in women with multiple sclerosis treated with natalizumab: I: fetal risks. Neurology. 2018;90(10):e823-e31.

109. Friend S, Richman S, Bloomgren G, Cristiano LM, Wenten M. Evaluation of pregnancy outcomes from the Tysabri(R) (natalizumab) pregnancy exposure registry: a global, observational, follow-up study. BMC Neurol. 2016;16(1):150.

110. Ebrahimi N, Herbstritt S, Gold R, Amezcua L, Koren G, Hellwig K. Pregnancy and fetal outcomes following natalizumab exposure in pregnancy. A prospective, controlled observational study. Mult Scler. 2015;21(2):198-205.

111. Oh J, Achiron A, Celius EG, Chambers C, Derwenskus J, Devonshire V, et al. Pregnancy outcomes and postpartum relapse rates in women with RRMS treated with alemtuzumab in the phase 2 and 3 clinical development program over 16 years. Mult Scler Relat Disord. 2020;43:102146.

112. Proschmann U, Thomas K, Thiel S, Hellwig K, Ziemssen T. Natalizumab during pregnancy and lactation. Mult Scler. 2018;24(12):1627-34.

113. Bragnes Y, Boshuizen R, de Vries A, Lexberg $\AA$, Østensen $\mathrm{M}$. Low level of rituximab in human breast milk in a patient treated during lactation. Rheumatology (Oxford). 2017;56(6):1047-8.

\section{Publisher's Note}

Springer Nature remains neutral with regard to jurisdictional claims in published maps and institutional affiliations. 